\title{
Towards a sensory congruent beer bottle: Consumer associations between beer brands, flavours, and bottle designs
}

\author{
Anna Fenko ${ }^{a^{*}}$, Sanne Heiltjes ${ }^{a}$, Lianne van den Berg-Weitzel ${ }^{b}$ \\ a University of Twente \\ ${ }^{\mathrm{b}}$ Cartils \\ *Corresponding author e-mail: a.fenko@utwente.nl
}

\begin{abstract}
Sensory packaging design congruent with product and brand characteristics may be used as an innovative tool to communicate product and brand values to consumers and to enhance taste experience. This study investigated whether consumers associate sensory properties of beer bottles with certain brand values and beer flavours. Participants evaluated five beer products on a list of brand values, flavour characteristics and package characteristics. The results demonstrated that consumers systematically associate tactile and auditory characteristics of a bottle with certain brand values and specific beer flavours. The study creates a conceptual tool for designing brand congruent multisensory beer bottles.
\end{abstract}

Keywords: Multisensory packaging, sensory congruence, brand values, beer bottle

\section{Introduction}

The importance of multisensory experience (i.e., the engagement of multiple senses) in developing positive product and brand evaluation is increasingly recognized (e.g., Lindstrom, 2005; Krishna, 2012). Multisensory experience is facilitated by multisensory integration, which occurs when the information from several senses is congruent (Schifferstein \& Spence, 2007). Congruence refers to the degree of fit among sensory characteristics of a product (Bone \& Ellen, 1999; Peracchio \& Tybout, 1996).

People intuitively develop cross-modal associations, the tendency for a sensory stimulus in one modality to be associated with a sensory stimulus in another sensory modality (Parise \& Spence, 2013). These associations raise consumer expectations about which combinations of stimuli tend to co-occur. For example, red colour is associated with sweet scent, while green 
colour is associated with fresh scent (Garber, Hyatt, \& Starr, 2001). Therefore, consumers expect perfume in a red packaging to have a sweet scent and perfume in a green packaging to have a fresh scent (Scharf \& Volkmer, 2000).

Cross-modal associations could be naturally present when stimuli share basic dimensions of sensory experience (Keetels \& Vroomen, 2011) or can be learned through repeated exposure to certain stimuli in certain contexts (Krisnha, Elder \& Caldara, 2010). For example, many people associate a citrus scent with cleaning behaviour from repeated exposure to a citrus scenting detergent (Holland, Hendriks \& Aarts, 2005).

\subsection{Multisensory packaging}

Sensory characteristics of the packaging may create certain product expectations and enhance the actual consumer experience. Researchers have demonstrated that packaging colours and shape can change the consumers' perception of the product within (Spence \& Piqueras-Fiszman, 2012). For instance, people match carbonated water with angular shapes and still water with round shapes (Spence \& Gallace, 2011). Furthermore, people match dark chocolate with angular shapes and milk chocolate with rounded shapes (Ngo, Misra \& Spence, 2011).

When sensory packaging characteristics are congruent with product or brand attributes, multisensory integration is facilitated, resulting in a more positive consumer experience. For example, soft drink 7-Up was evaluated as tasting better when yellow was added to the original green of the cans (Hine, 1995). Potato chips were perceived as crispier when the packaging made a noisier rustling sound (Spence, Shankar, \& Blumenthal, 2011). The taste of water was evaluated higher when it was served in a firm rather than a flimsy cup (Krishna \& Morrin, 2008). Thus, multisensory packages that match product characteristics create a more positive product experience (Schifferstein \& Spence, 2007).

Brand values can also be congruent with certain sensory stimuli. Brands position themselves by communicating their values (i.e., the attributes they stand for) to the target group (Meffert, Burmann \& Kirchgeorg, 2008). For example, masculinity and femininity are known brand values used to position a brand (Grohmann, 2009). Smooth paper congruent with femininity was evaluated more positively when a feminine smell was present, while a masculine smell led to more positive evaluations of rough paper congruent with masculinity (Krishna et al., 2010). Therefore, a female perfume brand is perceived as more feminine and evaluated more positively in a smooth packaging, while a male perfume brand is perceived as more masculine and evaluated more positively in a rough packaging.

\subsection{Research objective}

While the number of studies into the effects of sensory package characteristics on taste expectations is growing (see Piqueras-Fiszman \& Spence, 2015 for a review), less attention is paid to the effects of package design on brand experience (Meffert et al., 2008). Surprisingly, no attempts at all have been made to study the three-way interactions between the sensory 
elements in package design, brand experience and taste expectations. Therefore, with this study we aim to close this gap by investigating consumer associations between sensory characteristics of a package (beer bottle), brand values and taste expectation. The study can serve as the first step in designing a brand-congruent multisensory beer bottle.

\section{Method}

\subsection{Participants}

Dutch participants ( $N=42 ; 21$ men) were recruited via Facebook social network. The age varied from 18 to 56 years, mean age was $27(S D=9.4)$. The sample was higher educated compared to the general population ( $52,3 \%$ possessed a university degree; $26,2 \%$ completed a higher professional education; $9,5 \%$ had a secondary professional degree and $12 \%$ had a high school diploma). The majority of participants were regular consumers of beer: $57,1 \%$ consumed beer on a weekly basis; $21,4 \%$ monthly; $14,3 \%$ a few times a year; and $7,2 \%$ never drank beer.

\subsection{Stimuli}

Five pictures of distinctive beer bottles from existing foreign brands (Russian, Bulgarian, US and two Brazilian brands), unfamiliar to the target population, were presented to participants (see Figure 1). Participants' familiarity with the selected brands was further controlled with the questionnaire.

\subsection{Measures}

Verbal descriptions of brand values were extracted from the brand manuals of 32 beer brands across the world. The 27 brand values, which were claimed by two or more brands, were used in the survey (e.g., modern, social, fun, energizing, young, reliable, fresh, etc.). Taste descriptors that are used to describe pilsners were derived from a variety of beer brands ( $\mathrm{N}=29)$. The 15 taste descriptors, which were claimed by two of more beer brands, were used in the survey (e.g., slightly bitter, refreshing, full-bodied, crispy, smooth, etc.). In addition, 6 smell descriptors used to describe the beer aroma were included in the survey. Participants evaluated each of the five beer bottles on the 27 brand values on a 7-point Likert scale (from 1 'strongly disagree' to 7 'strongly agree'), taste and smell expectations for these products on a 7-point Likert scale (from 1 'strongly disagree' to 7 'strongly agree). They also evaluated their tactile and auditory expectations of the bottles on 5 tactile and 4 auditory attributes on 7-point bipolar scales (such as warm/cold, hard/soft, loud/quiet, etc.). 

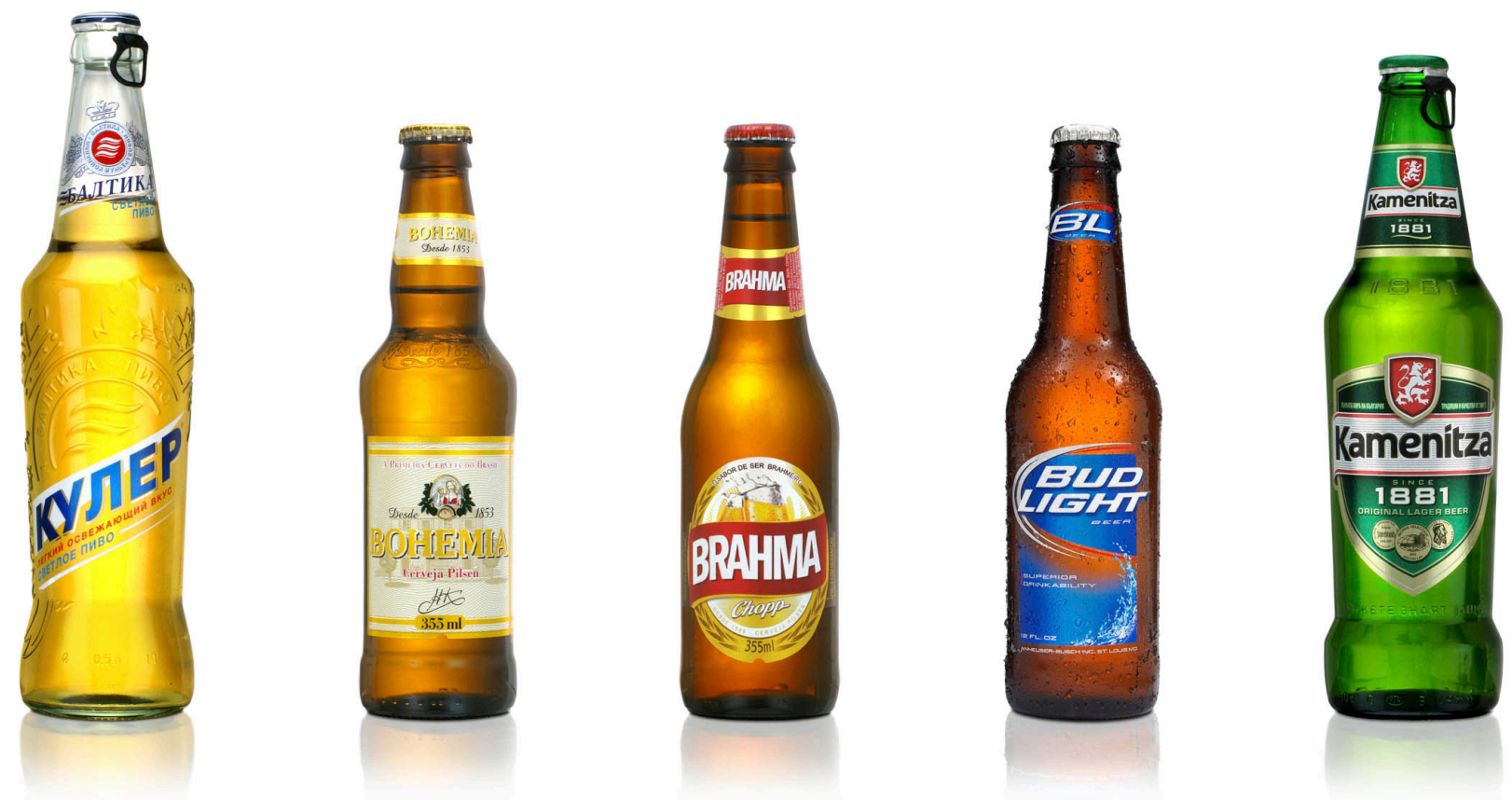

Figure 1 Beer bottles presented to participants. Starting left: Baltika Cooler(Russia), Bohemia (Brazil), Brahma (Brazill), Bud Light (USA) and Kamenitza (Bulgaria).

\subsection{Procedure}

Participants completed an online survey at home. The data were collected using ThesisTools online survey tool. Participants clicked on a link that directed them to the online survey. To comply with ethical regulations, they first stated their age and confirmed that no individuals younger than 18 were present in the room at the time of the survey. After answering demographic questions, participants were presented with the picture of the first foreign beer bottle. Participants indicated if they were familiar with the brand presented to them and if they had consumed this product before. Only a handful of participants indicated that they had previous knowledge about one of the brands, ranging between five respondents who were familiar with Bud Light to one who was familiar with Kamenitza. Thereafter, participants evaluated the beer bottle on the list of statements about the brand values, tactile and auditory characteristics of a bottle and their taste expectations. The questions were repeated for the other four brands. The order of the presentation was randomized between participants. The survey took approximately 20 minutes per participant.

\section{Results}

A Principal Components Analysis (PCA) with Varimax rotation was conducted on the brand value data to identify underlying brand dimensions. The analysis resulted in a 6 components solution accounting for $75 \%$ of the variance (see Table 1 ). The components were labelled as (1) dynamism; (2) excellence; (3) authenticity; (4) accessibility; (5) authority; and (6) uniqueness. For each brand value dimension the mean score was computed. 
Subsequently, a multiple regression analysis (MRA) was conducted to establish correlations between the brand value scores and tactile, auditory, olfactory and taste attributes. The conventions of Cohen (1988) were used to interpret the value of the correlations: $r=.10$ was interpreted as a small effect, $r=.30$ as a medium effect and $r=.50$ as a large effect. Table 2 presents the significant correlations between the six brand value dimensions, beer taste and smell descriptions and sensory package characteristics.

Table 1 Rotated component matrix with loadings and cumulative variances

\begin{tabular}{|c|c|c|c|c|c|c|}
\hline & \multicolumn{6}{|c|}{ Component } \\
\hline & $\begin{array}{l}1 \\
\text { dynamism }\end{array}$ & $\begin{array}{l}2 \\
\text { excellence }\end{array}$ & $\begin{array}{l}3 \\
\text { authenticity }\end{array}$ & $\begin{array}{l}4 \\
\text { accessibility }\end{array}$ & $\begin{array}{l}5 \\
\text { authority }\end{array}$ & $\begin{array}{l}6 \\
\text { uniqueness }\end{array}$ \\
\hline Energizing & .87 & & & & & \\
\hline Young & .86 & & & & & \\
\hline Fun & .79 & & & & & \\
\hline Fresh & .78 & & & & & \\
\hline Modern & .77 & & & & & \\
\hline Relaxed & .56 & & & & & \\
\hline Quality & & .84 & & & & \\
\hline Passionate & & .78 & & & & \\
\hline Prestige & & .75 & & & & \\
\hline Reliable & & .72 & & & & \\
\hline Premium & & .62 & & & & \\
\hline Successful & & .60 & & & & \\
\hline National pride & & & .83 & & & \\
\hline Authentic & & & .72 & & & \\
\hline Traditional & & & .68 & & & \\
\hline Hospitable & & & & .85 & & \\
\hline Friendly & & & & .77 & & \\
\hline Self-conscious & & & & & .79 & \\
\hline Bold & & & & & .72 & \\
\hline Masculine & & & & & .62 & \\
\hline Original & & & & & & .75 \\
\hline Distinctive & & & & & & .54 \\
\hline $\begin{array}{l}\text { Cumulative \% } \\
\text { variance }\end{array}$ & 35.36 & 56.29 & 62.51 & 67.56 & 71.56 & 75.34 \\
\hline
\end{tabular}


Table 2 Correlations between the brand value dimensions and sensory attributes

\begin{tabular}{|c|c|c|c|c|c|c|c|}
\hline & & \multicolumn{6}{|c|}{ Brand values } \\
\hline \multicolumn{2}{|c|}{ Sensory modality } & Dynamism & Excellence & Authenticity & Accessibility & Authority & Uniqueness \\
\hline \multirow[t]{5}{*}{ Touch } & Cold/warm & $-.20 *$ & $-.17 *$ & & & & \\
\hline & Flimsy/firm & & $.36 * *$ & $.43^{* *}$ & & $.30 * *$ & \\
\hline & Soft/hard & $-.20 *$ & & $.27^{* *}$ & & $.20^{*}$ & \\
\hline & Smooth/rough & & & & & & $-.20 *$ \\
\hline & Light/heavy & $-.34 * *$ & $.18^{*}$ & $.33 * *$ & $-.17^{*}$ & $.33^{* *}$ & \\
\hline \multirow[t]{2}{*}{ Sound } & $\begin{array}{l}\text { Opening } \\
\text { (quiet/loud) }\end{array}$ & $-.17^{*}$ & $.19^{*}$ & $.24 * *$ & & $.23^{* *}$ & \\
\hline & $\begin{array}{l}\text { Carbonation } \\
\text { (weak/strong) }\end{array}$ & & $.21^{*}$ & & & $.27^{* *}$ & $.24^{* *}$ \\
\hline \multirow[t]{7}{*}{ Smell } & Fruity & $.37 * *$ & & & $.26 * *$ & & \\
\hline & Floral & $.23^{* *}$ & & & $.18^{*}$ & & \\
\hline & Spicy & $-.17^{*}$ & & $.27^{* *}$ & & $.23 * *$ & \\
\hline & Sweet & $.28 * *$ & & & $.17^{*}$ & & \\
\hline & Bitter & $-.24 * *$ & $.39 * *$ & $.45^{* *}$ & & $.34 * *$ & \\
\hline & Intense & & $.62 * *$ & $.56^{* *}$ & $.20^{*}$ & $.61^{* *}$ & $.42 * *$ \\
\hline & Subtle & $.37 * *$ & & & $.25 * *$ & & \\
\hline \multirow[t]{15}{*}{ Taste } & Bitter & $-.24 * *$ & $.40 * *$ & $.45^{* *}$ & & $.48^{* *}$ & $.19 *$ \\
\hline & Refreshing & $.63 * *$ & $.32 * *$ & & $.31 * *$ & $.30 * *$ & $.40 * *$ \\
\hline & Full-bodied & & $.61^{* *}$ & $.57 * *$ & $.18^{*}$ & $.61^{* *}$ & $.37 * *$ \\
\hline & Smooth & $.38 * *$ & & & $.46^{* *}$ & & $.25^{* *}$ \\
\hline & Crispy & & & & & $.21 *$ & \\
\hline & Foamy & & $.19 *$ & & & $.23^{* *}$ & $.20 *$ \\
\hline & Easy to drink & $.52^{* *}$ & & $-.18^{*}$ & $.40 * *$ & & $.17^{*}$ \\
\hline & Light & $.46 * *$ & $-.22 * *$ & $-.44 * *$ & $.27^{* *}$ & $-.23 * *$ & \\
\hline & Natural & & $.31 * *$ & $.27 *$ & $.41 * *$ & & $.24 * *$ \\
\hline & Mild & $.32 * *$ & & -.22 & $.18^{*}$ & & \\
\hline & $\begin{array}{l}\text { Thirst- } \\
\text { quenching }\end{array}$ & $.44^{* *}$ & $.28 * *$ & & $.43^{* *}$ & $.23^{* *}$ & $.23^{* *}$ \\
\hline & Sweet & $.42 * *$ & & $-.30 * *$ & $.22 * *$ & & \\
\hline & Tingly & & & & $.19 *$ & & \\
\hline & Watery & $.18^{*}$ & $-.53 * *$ & $-.46 * *$ & & $-.49 * *$ & $-.28 * *$ \\
\hline & Sharp & $-.21 *$ & $.26 * *$ & $.33 * *$ & & $.26 * *$ & \\
\hline
\end{tabular}

Note: * Correlation is significant at .05 level; ${ }^{* *}$ Correlation is significant at .01 level; $N=140$. 
The results demonstrate a clear pattern of semantic congruence between sensory characteristics of bottles, brand values, and taste expectations of beer. Brands representing excellence, authenticity and authority show similar pattern of associations with sensory package characteristics, indicating congruence with firm and heavy packages, loud opening sound and strong carbonation sound. Dynamic and accessible brands are associated with the opposite package characteristics, i.e., light packages and quiet opening sound. These two groups of brand values also show different patterns of taste expectations. Brands representing excellence, authenticity and authority are associated with intense bitter smell and full-bodied bitter taste, while dynamic and accessible brands are associated with subtle, sweet, fruity and floral smells and smooth, light and easy to drink taste.

\section{Discussion}

The study has demonstrated that consumers systematically associate sensory characteristics of beer bottles with certain brand values and specific taste expectations.

In our study brand values were structured in six groups that share one of the six underlying dimensions: dynamism, excellence, authenticity, accessibility, authority and uniqueness. Our results suggest that sensory packaging design would be especially useful to differentiate brands that represent excellence, authenticity, and authority from dynamic and accessible brands. Weight, texture and an opening sound of a bottle are especially promising sensory characteristics that can be implemented in a brand-congruent multisensory packaging to communicate specific brand values and reinforce taste expectations.

The congruence between brand value of excellence and heavy and firm packaging is in line with previous findings, where heaviness and firmness were found to be associated with high quality, while lightness and flimsiness were found to be associated with lower quality (Krishna \& Morrin, 2008; Lindstrom, 2005; Piqueras-Fiszman \& Spence, 2011). Moreover, dynamic and accessible brands were associated with quiet sounds, while brand values of excellence, authenticity, and authority were associated with loud sounds. These results contribute to the growing body of research on product-sound associations (Parise \& Spence, 2009; Spence, 2012; Spence \& Gallace, 2011; Spence, Shankar, \& Blumenthal, 2011; Yorkston \& Menon, 2004;).

Our data has demonstrated that consumers perceive certain sensory attributes of a package as congruent and other attributes as incongruent with specific brand values. We suggest that in designing product packages, it is important to use sensory characteristics that are congruent with brand values. A brand-congruent packaging design may enhance consumer experience. Congruent stimuli are generally evaluated more positively, because fast and effortless processing of these stimuli is experienced as more pleasant (Gottfried \& Dolan, 2003; Lee \& Labroo, 2004). Moreover, people like products (e.g., food and drinks) more, when the products are predictable and confirm their expectations (Cardello, 1994; Deliza \& 
MacFie, 1997; Meyers-Levy \& Tybout, 1989). Sensory congruence helps to set realistic expectations among consumers, which makes products more predictable and more enjoyable.

Our study was the first attempt to systematically investigate three-way relationships between brand values, sensory package characteristics and product expectations. It makes the first step in transforming abstract brand concepts into concrete consumer experiences with the help of sensory packaging design. The study was performed in the area of beer brands, but may have practical implications for other fast-moving consumer goods that are known to depend heavily on the perceived brand properties (Schmitt \& Simonson, 1997). Adding new multisensory dimensions to consumer experience enables brands to compete for consumer attention and loyalty (Pine \& Gilmore, 1999;). Our results can help designers and brand managers to select sensory package characteristics that reflect their brand values and help to create a more pleasurable consumer experience.

\section{References}

Bone, P. F., \& Ellen, P. S. (1999). Scents in the marketplace: Explaining a fraction of olfaction. Journal of Retailing, 75(2), 243-262.

Cardello, A. V. (1994). Consumer expectations and their role in food acceptance. In H. J. H. MacFie, \& D. M. H. Thomson (Eds.), Measurement of food preferences (pp. 253-297). London: Blackie Academic \& Professional.

Cohen, J. (1988). Statistical power analysis for the behavioral sciences. Hillsdale: Erlbaum

Deliza, R., \& MacFie, H. J. H. (1997). The generation of sensory expectation by external cues and its effect on sensory perception and hedonic ratings: A review. Journal of Sensory Studies, 2, 103-128.

Garber, L. L., Hyatt, E. M., \& Starr, R. G. (2001). Placing food color experimentation into a valid consumer context. Journal of Food Products Marketing, 7(3), 3-24.

Gottfried, J. A., \& Dolan, R. J. (2003). The nose smells what the eye sees: Crossmodal visual facilitation of human olfactory perception. Neuron, 39 (2), 375-386.

Grohmann, B. (2009). Gender dimensions of brand personality. Journal of Marketing Research, 46(1), 105-119.

Hine, T. (1995). The total packaging: The secret history and hidden meanings of boxes, bottles, cans and other persuasive containers. New York, NJ: Little Brown.

Holland, R. W., Hendriks, M., \& Aarts, H. (2005). Smells like clean spirit. Psychological Science, 16(9), 689.

Keetels, M., \& Vroomen, J. (2011). No effects synesthetic congruency on temporal ventriloquism. Attention, Perception, \& Psychophysics, 73, 209-218.

Krishna, A. \& Morrin, M. (2008). Does touch affect taste? The perceptual transfer of product container haptic cues. Journal of Consumer Research, 34(6) 807-818.

Krishna, A. (2012). An integrative review of sensory marketing: Engaging the senses to affect perception, judgment and behavior. Journal of Consumer Psychology, 22, 332-351.

Krishna, A., Elder, R. S., \& Caldara, C. (2010). Feminine to smell but masculine to touch? Multisensory congruence and its effect on t the aesthetic experience. Journal of Consumer Psychology, 20, 410418. 
Lee, A.Y., \& Labroo, A.A. (2004). The effect of conceptual and perceptual fluency on brand Evaluation. Journal of Marketing Research, 41(5), 151-65.

Lindstrom, M. (2005). Brand sense: Sensory secrets behind the stuff we buy. New York: Free Press.

Meffert, H., Burmann, C., \& Kirchgeorg, M. (2008). Marketing: Grundlagen Marktorientierter Unternehmensführung. Konzepte - Instrumente - Praxisbeispiele. [Marketing: Principles of marketoriented corporate governance. Concepts - Tools - Practical examples]. Wiesbaden: Gabler Verlag. (In German).

Meyers-Levy, J., \& Tybout, A. M. (1989). Schema congruity as a basis for product evaluation. The Journal of Consumer Research, 16(1), 39-54.

Ngo, M., Misra, R., \& Spence, C. (2011). Assessing the shapes and speech sounds that people associate with chocolate samples varying in cocoa content. Food Quality \& Preference, 22, 567572.

Parise, C. V., \& Spence, C. (2009). 'When birds of a feather flock together': Synesthetic correspondences modulate audiovisual integration in non-synesthetes, PLOS ONE, 4(5), pp 1-7.

Parise, C. V., \& Spence, C. (2013). Audiovisual crossmodal correspondences. J. Simner \& E. Hubbard (Eds.), Oxford handbook of synaesthesia (pp. 790-815). Oxford: Oxford University Press.

Peracchio, L. A., \& Tybout, A. M. (1996). The moderating role of prior knowledge in schema-based product evaluation. Journal of Consumer Research, 23, 177.

Pine, B. J., \& Gimore, J. H. (1999). The experience economy: Work is theatre and every business a stage. Boston: Harvard Business School Press.

Piqueras-Fiszman, B., \& Spence, C. (2012). Crossmodal correspondences in product packaging: Assessing color-flavor correspondences for potato chips (crisps). Appetite, 57, pp 753-757.

Piqueras-Fiszman, B., \& Spence, C. (2015). Sensory expectations based on product-extrinsic food cues: An interdisciplinary review of the empirical evidence and theoretical accounts. Food Quality and Preference, 40, pp 165-179.

Scharf, A., \& Volkmer, H. P. (2000). The impact of olfactory product expectations on the olfactory product experience. Food Quality and Preference, 11, 497-503.

Schifferstein, H. N. J. \& Spence, C. (2007). Multisensory product experience. In: H. N. J. Schifferstein \& P. Hekkert, (Eds.), Product experience (pp. 133-161). Amsterdam: Elsevier.

Schmitt, B. H. \& Simonson, A. (1997). Marketing aesthetics: The strategic management of brands, identity, and image. New York: The Free Press.

Spence, C. (2012). Managing sensory expectations concerning products and brands: Capitalizing on the potential of sound and shape symbolism. Journal of Consumer Psychology, 22, pp 37-54.

Spence, C., \& Gallace, A. (2011). Multisensory design: Reaching out to touch the consumer. Psychology and Marketing, 28(3), pp 267-308.

Spence, C., Shankar, M. U., \& Blumenthal, H. (2011). 'Sound bites': auditory contributions to the perception and consumption of food and drink. In F. Bacci \& D. Mecher (Eds), Art and the senses (p. 207-238). Oxford: Oxford University Press.

Yorkston, E. A., \& Menon, G. (2004). A sound idea: Phonetic effects of brand names on consumer judgements. Journal of Consumer Research, 31, pp 43-51.

About the Authors:

Anna Fenko is an assistant professor of Marketing Communication and Consumer Behaviour at the University of Twente. She obtained 
PhD in design research at Delft University of Technology. Her research interests include multisensory marketing, packaging design and food experience.

Sanne Heiltjes MSc graduated in Communication Science at the University of Twente and Psychology at Radboud University. As a market researcher at Ipsos she specialises in innovation of fastmoving consumer goods. Her interests include subconscious consumer behaviour and multisensory marketing.

Lianne van den Berg-Weitzel MSc is Professional Development Director at CARTILS Branding \& Packaging Design Consultants. Her aim is to build a strong fundament for the creative profession of packaging design by doing scientific research together with leading universities. 